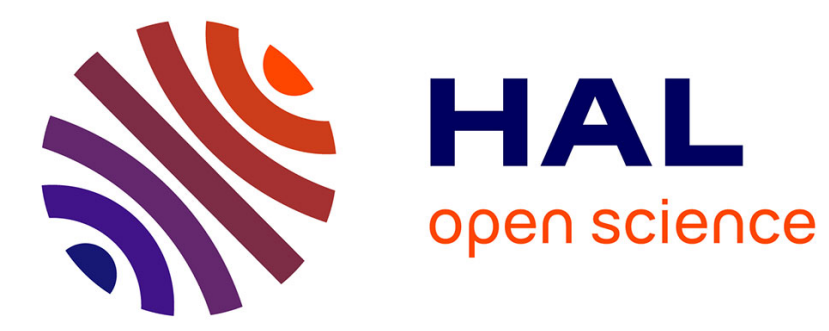

\title{
Dynamic properties and spall plane formation of brass
}

\author{
H. Nahme, M. Worswick
}

\section{To cite this version:}

H. Nahme, M. Worswick. Dynamic properties and spall plane formation of brass. Journal de Physique IV Proceedings, 1994, 04 (C8), pp.C8-707-C8-712. 10.1051/jp4:19948108 . jpa-00253349

\section{HAL Id: jpa-00253349 https://hal.science/jpa-00253349}

Submitted on 1 Jan 1994

HAL is a multi-disciplinary open access archive for the deposit and dissemination of scientific research documents, whether they are published or not. The documents may come from teaching and research institutions in France or abroad, or from public or private research centers.
L'archive ouverte pluridisciplinaire HAL, est destinée au dépôt et à la diffusion de documents scientifiques de niveau recherche, publiés ou non, émanant des établissements d'enseignement et de recherche français ou étrangers, des laboratoires publics ou privés. 


\title{
Dynamic properties and spall plane formation of brass
}

\author{
H. Nahme and M.J. Worswick* \\ Ernst-Mach-Institute, Eckerstrasse 4, 79104 Freiburg, Germany \\ * Carleton University, Department of Mechanical and Aerospace Engineering, C.J. Mackenzie Building, \\ Ottawa, Canada, KIS $5 B 6$
}

\begin{abstract}
Résumé
Pour mieux comprende les processus de la formation des fissures y compris la nucléation des cavités, la croissance et la coalescence et l'évolution des fissures, des expériences d'impacts de plaque ont été effectuées en combinaison avec la technique VISAR. Une attention particulière a été portée aux conditions de l'impact autour du seuil de l'écaillage. Trois types des échantillons du laiton contenant du plomb ont été choc-chargés au niveau de contrainte 0.85 $\mathrm{GPa}<\sigma<3.8 \mathrm{GPa}$. Des données d'Hugoniot ont été obténues par des courbes vitesse temps. Des échantillons récupérés ont été examinés par des méthodes métallographiques et par la microscopie électronique à balayage. Les données des matériaux dynamiques servent de données d'entrée pour les calculs 2D LS-DYNA en utilisant un modèle de comportement basé sur la fonction d'écroussage de Gurson.
\end{abstract}

\begin{abstract}
For a better understanding of crack forming processes including void nucleation, growth and coalescence and the evolution of cracks, planar plate impact experiments in combination with VISAR- technique have been performed. Special attention was focused to impact conditions around the spall threshold. Three types of lead-containing brass samples were shock loaded to stress levels $0.85 \mathrm{GPa}<\sigma<3.8 \mathrm{GPa}$. From the measured velocity-time-histories Hugoniot data were obtained. Recovered samples have been examined by means of metallographic methods and scanning electron microscopy. The dynamic material data serve as input data for IS-DYNA 2D-calculations employing a Gurson-based constitutive model.
\end{abstract}

\section{Introduction}

Material forming processes at high strain rates like explosive forming and impact processes may cause nucleation of microvoids. These voids may grow and coalesce under conditions of high stress at high strain rates. Modeling the processes finally leading to ductile fracture at high strain rates numerically by means of existing finite element codes is still not resolved to a sufficient level of accuracy. It has been shown that implementation of the Gurson constitutive model into the existing LS-DYNA-2D-code yields fairly good conformity between numerical and experimental data concerning the spallation process investigated by means of planar plate impact tests $/ 1 /$. Also the void nucleation and growth in SHPB-tests is described quite well $/ 2 \%$. Nevertheless remaining differences between experimental and numerical results require improved experimental input data for the calculations. In this paper the dynamic properties of different brass materials have been determined. The results serve as input data for the numerical calculations described elsewhere in this volume $/ 3 /$. 


\section{Experimental Setup and Data Reduction}

The materials under investigation were UNS C36000 free cutting brass annealed for two hours at $600^{\circ} \mathrm{C}$ and $850^{\circ} \mathrm{C}$ respectively and MS 58, not heat treated. Both types of brass contain lead particles at an overall concentration of $2 \%$. The heat treatment has been done to spherodize the lead particles.

The dynamic properties of the materials have been determined by means of planar plate impact technique in combination with a VISAR /4/ and sample recovery techniques. Brass plates of $8 \mathrm{~mm}$ thickness and $50 \mathrm{~mm}$ diameter mounted in a precisely adjustable sample holder have been impacted by projectile plates of $3 \mathrm{~mm}$ thickness and $58 \mathrm{~mm}$ diameter made of the same material. The projectile plates have been accelerated to velocities of $53 \mathrm{~m} / \mathrm{s}<\mathrm{v}<230 \mathrm{~m} / \mathrm{s}$ using a single stage compressed air gun with $70 \mathrm{~mm}$ bore diameter. The situation immediately before impact is shown in fig. 1 schematically. The tilt between both plates at the moment of impact was in the range of $1 \mathrm{mrad}$.

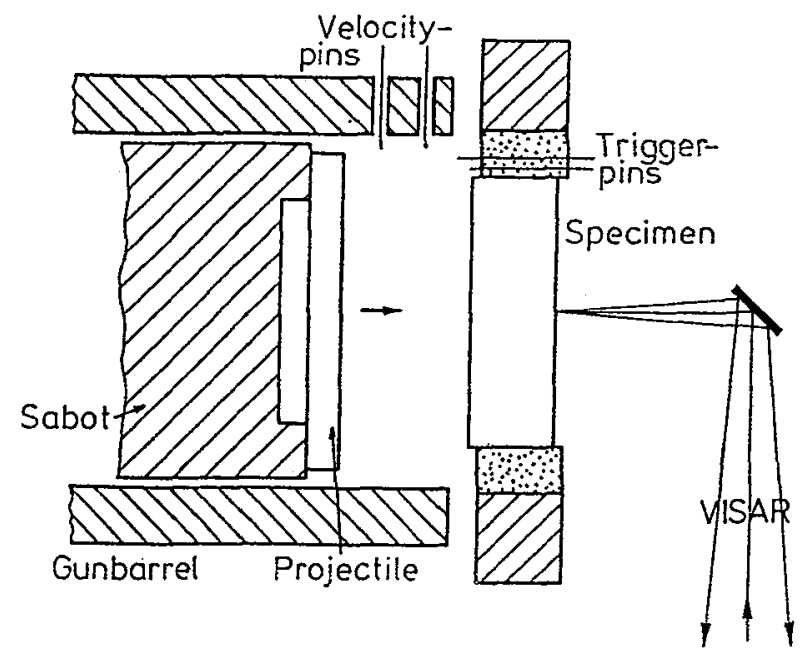

Figure 1: Experimental setup (schematically)

The impact causes pressure waves propagating from the impact plane into both the projectile and the target plate. The waves are reflected at the free surfaces and propagate back into the material as pressure release waves. Superposition of these release waves cause tensile stress inside the material. This leads to spallation for tensile stress levels exceeding the dynamic material tensile strength. The plate thicknesses have been chosen for spallation always taking place inside the target plate. With the VISAR the velocity of the target rear side has been recorded with a time resolution better than $5 \mathrm{~ns}$. From the measured velocity-time-histories the Hugoniot elastic limits have been determined according to

$$
\sigma_{\mathrm{HEL}}=\mathrm{u}_{\mathrm{HEL}} \rho_{\mathrm{o}} \mathrm{c}_{\mathrm{l}} / 2 .
$$

Maximum stress was calculated using

$$
\sigma_{\max }=\sigma_{\mathrm{HEL}}+\rho_{\mathrm{o}} \mathrm{U}_{\mathrm{s}}\left(\mathrm{u}_{\max }-\mathrm{u}_{\mathrm{HEL}}\right) / 2 \text {. }
$$

To determine the spall strength, the method given by Romanchenko and Stepanow /5/ was used yielding

$$
\begin{aligned}
& \sigma_{\mathrm{pb}}=\rho_{\mathrm{o}}\left(c_{1} c_{\mathrm{o}} /\left(c_{1}+c_{\mathrm{o}}\right)\right) \mathrm{u}_{\mathrm{pb}} \\
& \Delta \sigma_{\mathrm{pb}}=(\mathrm{x} / \tau)\left(1 / \mathrm{c}_{\mathrm{o}}-1 / \mathrm{c}_{1}\right) \sigma_{\mathrm{pb}} \\
& \sigma_{\mathrm{sp}}=\sigma_{\mathrm{pb}}+\Delta \sigma_{\mathrm{pb}}
\end{aligned}
$$

with the following notations: 


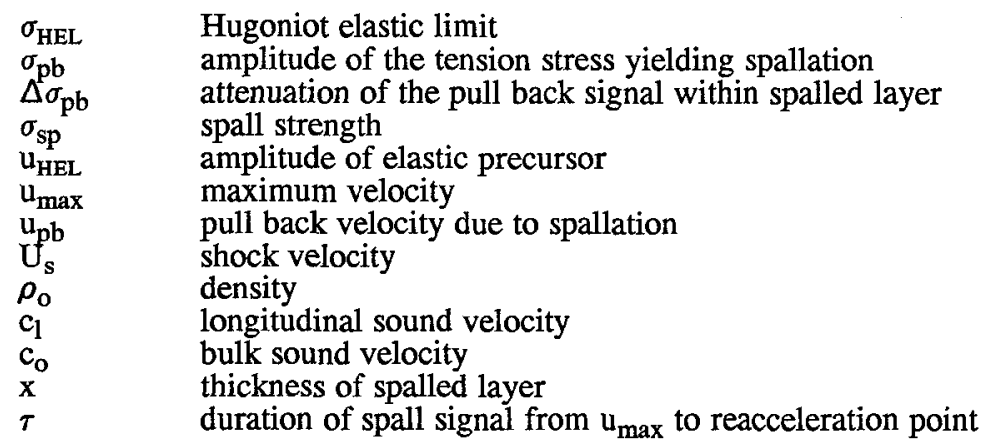

\section{Experimental Results and Discussion}

Figure 2 shows typical velocity-time-histories with and without spallation for all three materials. In most experiments the release waves from the projectile rear side contain different components. The release process starts at low strain rate until the velocity is reduced by an amount nearly equal to the

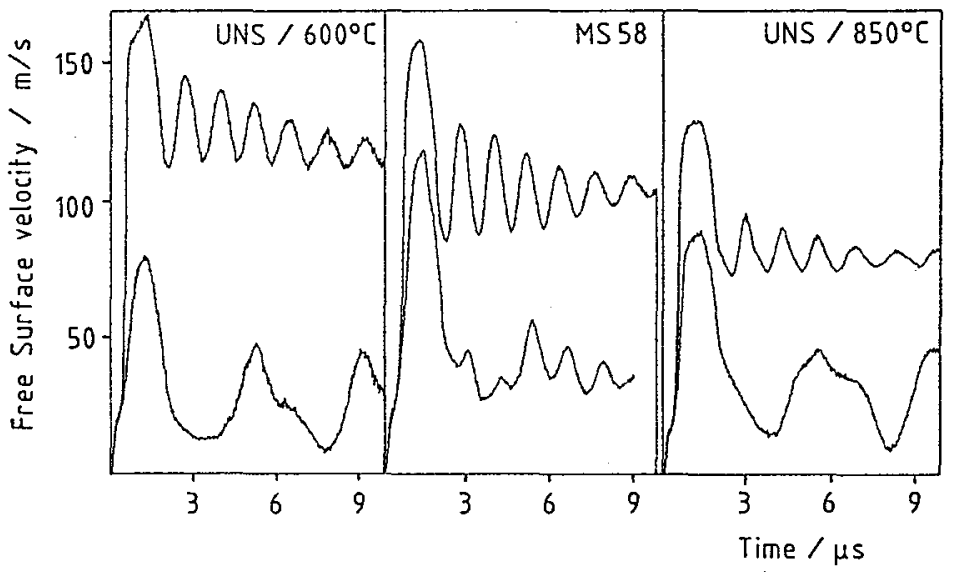

Figure 2: Velocity-time histories for all tested materials

elastic precursor. This part is followed by a release at higher strain rate. The remaining part of the release with the lowest strain-rate lasts until reacceleration occurs due to either tension release waves in the case of spallation or reflected pressure waves emanating from the impacted side of the target. The second and third part of the wave structure are visible also in the "ringing in spall" signal. An evolving spall plane prevents the fast elastic precusor from reaching again the target rear surface. The interpretation of the two remaining parts is not yet clear. The idea that at the end of the high strain rate part cracks begin to evolve can be ruled out from the microscopic examination of recovered samples. Also $\mathrm{v}(\mathrm{t})$-curves showing no spallation exhibit the "three wave structure" but no sign of evolving cracks have been found in these samples. For tests yielding no spallation, the shape of the velocity maxima of the "ringing in spall" signal strongly changes with time, indicating that all wave components are existing for a long time propagating with different velocities.

The observed wavestructure is most pronounced for the UNS C 36000 material annealed at $850^{\circ} \mathrm{C}$ but is observed for all 3 materials.

In fig. 3 the correlation between the shock velocity $U_{s}$ and the particle velocity $u_{p}$ is shown. The material annealed at $850^{\circ} \mathrm{C}$ and the MS 58 are quite well represented by a linear correlation. Only for the third material data are less consistent. There is no indication in the experimental data explaining these scattered data. Nevertheless these data are located between those of the two other materials indicating an effect of the annealing process also at $600^{\circ} \mathrm{C}$. The annealing process seems to increase the shock velocity of the brass material. Whether the annealing process at $600^{\circ} \mathrm{C}$ is responsible for the spread of the data is not yet clear and requires further investigation. 


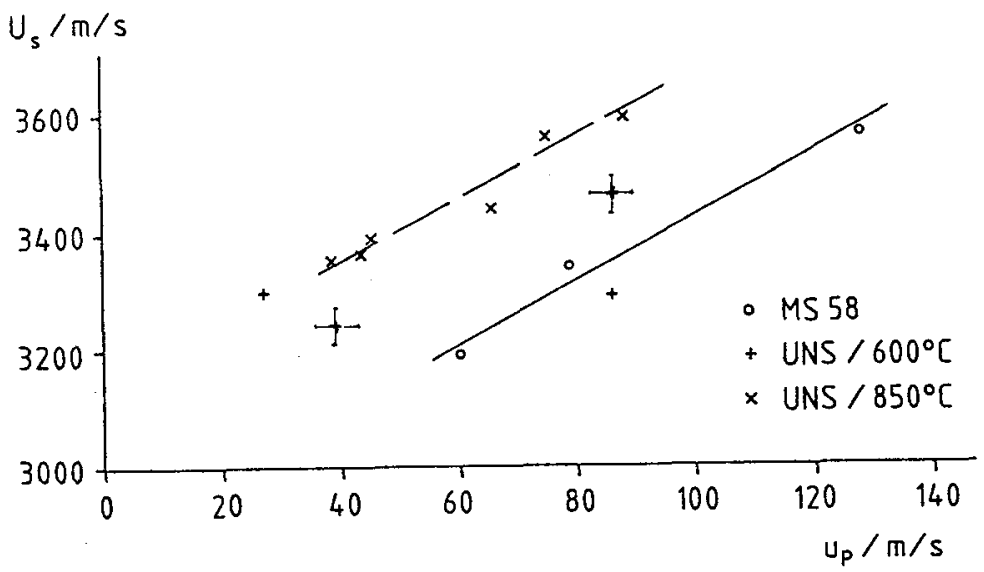

Figure 3: Shock velocity - particle velocity diagram

The stress-strain diagram (fig. 4) shows a nearly linear correlation for all three materials. Again the data for material annealed at $600^{\circ} \mathrm{C}$ are more scattered than for the other ones.

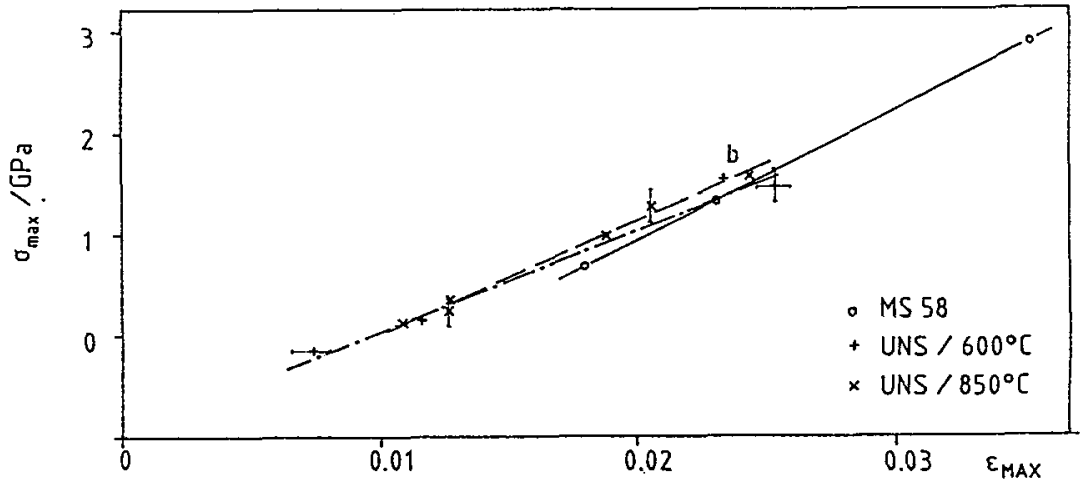

Figure 4: Stress - strain diagram

The derived values for $\sigma_{\mathrm{HEL}}$ and $\sigma_{\mathrm{sp}}$ are compiled in table 1 . The HEL-data slightly increase with increasing applied stress for MS 58 and decreases slightly for the two annealed materials. The data for the UNS $1600^{\circ} \mathrm{C}$ are located between those of the two other materials, indicating a reduction of the HEL due to the annealing process. The spall strength of both heat treated materials are nearly independent of the applied maximum stress but are lower than the values of the MS 58 brass.

\section{Table 1:}

Hugoniot elastic limit $\sigma_{\mathrm{HEL}}$; spall strength $\sigma_{\mathrm{sp}}$

\begin{tabular}{l|l|l} 
& $\sigma_{\mathrm{HEL}} / \mathrm{MPa}$ & $\sigma_{\mathrm{sp}} / \mathrm{GPa}$ \\
\hline UNS $36000 / 600^{\circ} \mathrm{C}$ & $253-340$ & $1.12-1.25$ \\
$\mathrm{UNS} 36000 / 850^{\circ} \mathrm{C}$ & $217-243$ & $1.14-1.25$ \\
MS 58 & $310-383$ & $1.61-1.61$
\end{tabular}

Concerning the spall strength data it should be mentioned that the highest values are measured for low stresses and are not really spall strengths but are the tension stress levels applied to the material without spallation occuring. Threshold for spallation may be somewhat higher, so that a slight decrease of the spall strength is probable. 
Figs. 5a displays stress-strain-rate correlations for all three materials. The slopes of the linear fits are $\mathrm{m}=2.56, \mathrm{~m}=2.43$ and $\mathrm{m}=2.05$ for UNS $/ 600^{\circ} \mathrm{C}$, UNS $/ 850^{\circ} \mathrm{C}$ and MS 58 respectively. All values are smaller than the value of $\mathrm{m}=4$ predicted by the $\epsilon=\mathrm{a} \sigma^{4}$ law given by Swegle and Grady $/ 6 /$.
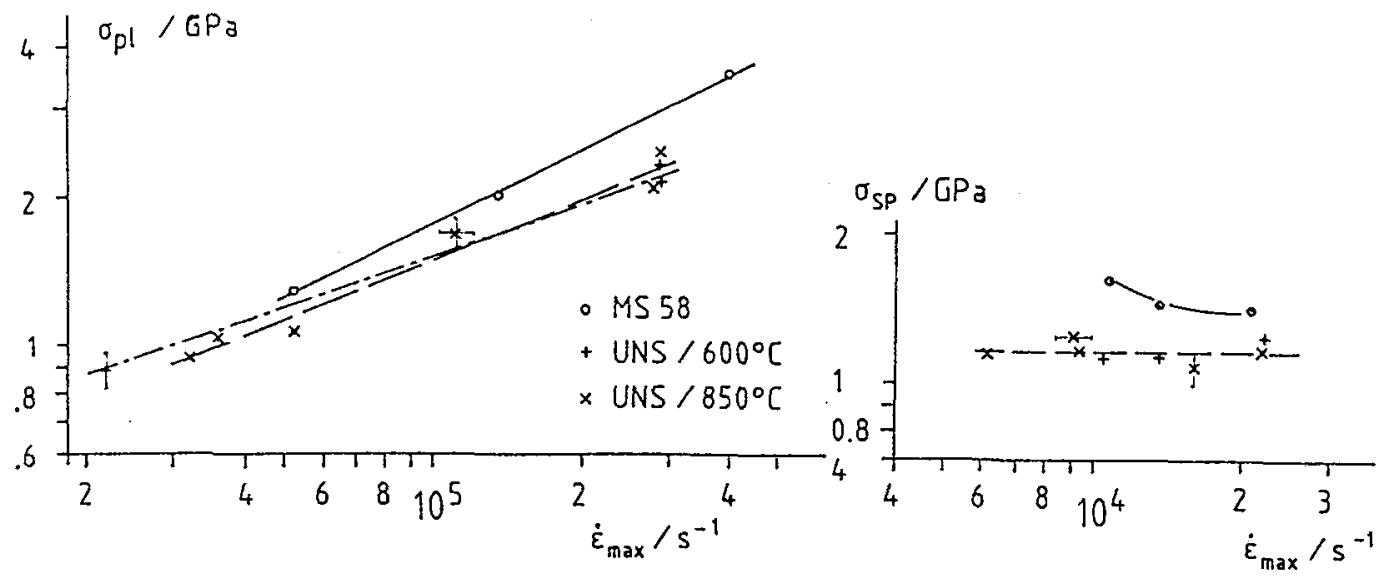

Figure 5:

a) Pressure stress - strain-rate diagram for compressing

b) Tensile stress - strain-rate diagram during spallation

Whether the different shapes of the lead particles are responsible for the differences is not clear yet. In fig. $5 \mathrm{~b}$ the correlation between the spall strength and the maximun strain-rate during spallation is shown in a similar plot. For the spall strength of the annealed materials nearly no strain-rate dependence was observed. For MS 58 a slightly decreaseing strength with increasing strain-rate is indicated.

The data derived from the plate impact experiments presented here serve as input data for the numerical simulation of the dynamic behavior including spallation. To describe the spall process a constitutive model based on Gurson's theory /7/ of plastic flow and fracture has been implemented into the LS DYNA-2D code. It has been shown previously that there is a fairly good agreement between some experimental $\mathrm{v}(\mathrm{t})$ curves and corresponding first results of the numerical calculations. Details of the numerical model, the results of Split Hopkinson Tensile Bar experiments and the comparison of experimental and numerical results are given elsewhere in this volume $/ 3 /$.

For one test with MS 58 brass the impact conditions nearly met the spall strength exactly (see fig.2). The amplitudes of the velocity maxima contain contributions of both the "ringing in spall" and "ringing in target" signals. This indicates that the spall process for these special conditions required at least $4 \mu \mathrm{s}$ to be completed. Only from $5.5 \mu \mathrm{s}$ the pure "ringing in spall"-signal is left.

Figs. 6a,b show optical micrographs of a cross-section of the sample. The spall crack just opened but there are regions where the spalled layer is still connected to the bulk material. The meandering crack covers a width of approximately $0.5 \mathrm{~mm}$. The shape of the crack together with the measured signal allows some assumptions as to how this crack evolved. The observation that cracks orientated parallel to the sample surfaces are connected by thin cracks allows the conclusion that the evolution of the crack may have happened in two steps. In a first step small cracks formed parallel to the plate surfaces. This is also to be seen near the ends of the main fracture. In a second step the randomly but parallel distributed cracks are connected by cracks caused by shear stress acting on the still remaining material bridges separating the small cracks. This scenario allows parts of the "ringing in target" signal to be transmitted across the still evolving crack until the bridges are broken too.

The examination of the lead particle distribution for samples showing no spallation shows no significant change in the lead particle distribution within the area the spallation would evolve. Only samples impacted at velocities leading to spallation show features that may be regarded as evolving cracks. Figs. 6c,d show two optical micrographs of MS 58 brass near the spall plane. Cracks are visible still being arrested in the bulk material. In several cases more or less straight lines of lead particles are visible which may be regarded as a first step of an evolving crack. It seems possible that 
these cracks have been stopped during their evolution when the main crack opened and tension stress release waves were created. These release waves then have reduced the forces acting on the cracks to open them.

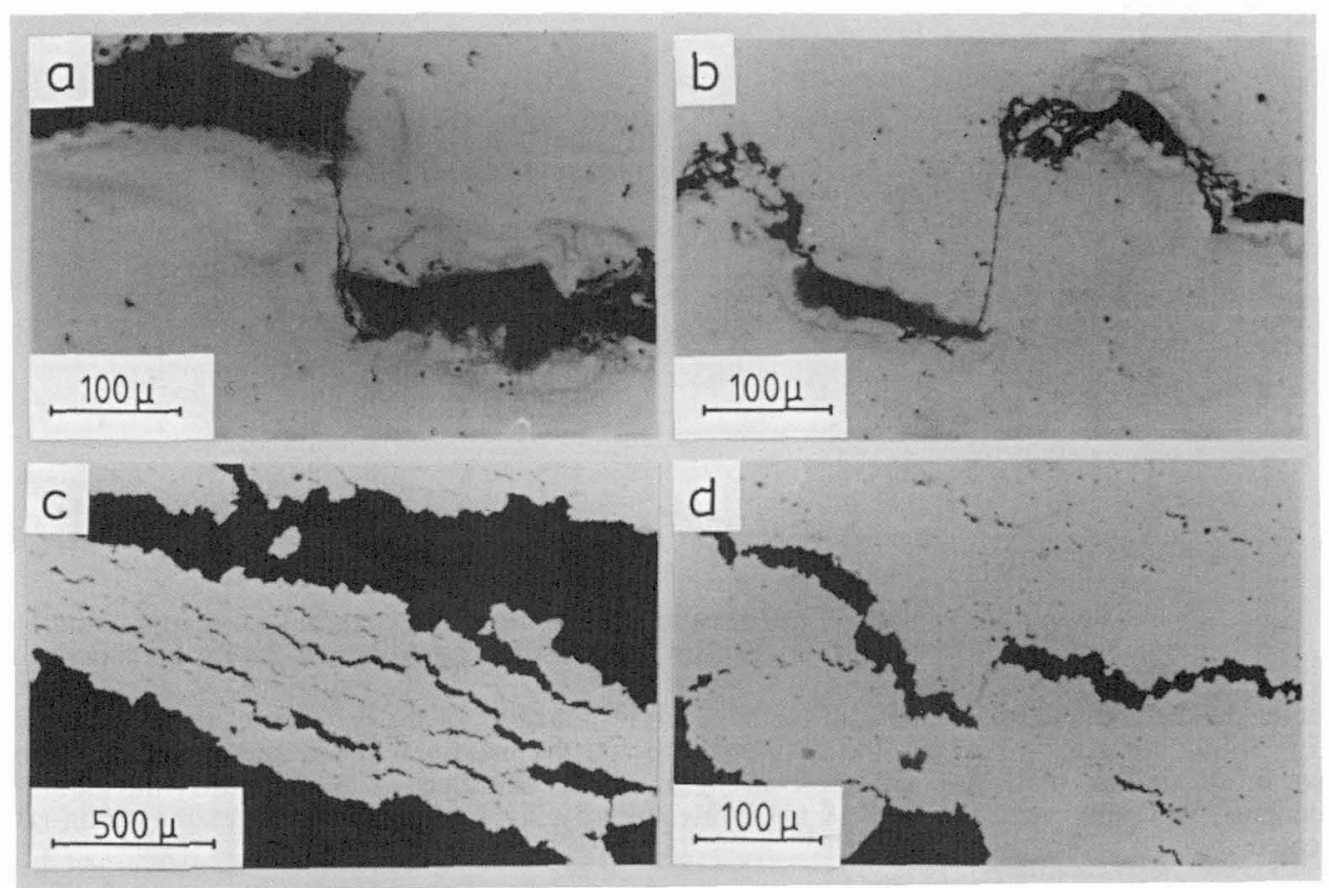

Figure 6: Optical micrographs of spall cracks

$a, b)$ near spall threshold

c,d) clearly above spall threshold

\section{Conclusion}

The experiments described yielded dynamic material data to be used in numerical modeling of the material behavior under high strain rate loading conditions. Postloading inspection of shock loaded samples together with the measured dynamic behavior provided insight into the spall plane formation process near spall threshold conditions.

\section{References}

/1/ M.J.Worswick, H.Nahme, J.Clarke, J. Fowler; Conf. Proc. DYMAT 8th Technical Conference, CEC Joint Research Centre ISPRA Oct. 12th-13th 1993, pp. 8.1

12/ M.J.Worswick, B.Wong, R.J.Pick

Conf. Proc. DYMAT 91, 3rd International Conference on Mechanical and Physical Behaviour of Materials under Dynamic Loading, Strasbourg Oct. 14th-18th 1991, (Les Editions de Physique, 1991), p.605

13/ M.J.Worswick, H.Nahme, J.Fowler, companion paper appearing in this volume

14/ L.M.Barker, R.F.Hollenbach; J. Appl. Phys. 43, 4669 (1972)

15/ V.I.Romanchenko, G.V.Stepanov; J. Appl. Mech. and Tech. Phys. 21, 555 (1980)

/6/ J.W.Swegle, D.E. Grady; J. Appl. Phys. 58, 692 (1985)

/7/ A.L.Gurson; Ph.D. Thesis, Brown University, 1975 